\title{
Ethnography, Its Strengths, Weaknesses and Its Application in Information Technology and Communication as a Research Design
}

\author{
Amuomo Nixon", Collins Otieno Odoyo ${ }^{2, *}$ \\ ${ }^{1}$ Department of Mathematics and Computing, School of Science, Technology and Engineering, Rongo University, P.O. Box 103-40404, \\ Rongo, Kenya \\ ${ }^{2}$ Department of Information Technology, School of Computing and Informatics, Masinde Muliro University of Science and Technology, \\ P.O. Box, 190 - 50100, Kakamega, Kenya
}

Received April 20, 2020; Revised May 21, 2020; Accepted June 23, 2020

Copyright $\subseteq 2020$ by authors, all rights reserved. Authors agree that this article remains permanently open access under the terms of the Creative Commons Attribution License 4.0 International License

\begin{abstract}
Ethnography was originally developed for the study of foreign cultures by the anthropologists. It involves the observation of situations and carrying out interviews with the study population. There are two basic characteristics of ethnography where the observation takes place in a natural setting and secondly, where researchers must understand how an event is perceived and interpreted by the people in a community. Ethnography is therefore a qualitative research method that is used to study people and cultures for in-depth knowledge about a socio-technological realities surrounding everyday software development practice. Ethnography can help to uncover not only what practitioners do, but also why they do it in terms of human computer interaction and user interfaces design. This is due to its unique strength to involve the researcher, the research process and the research, making it a potential ideal method for undertaking research where the community and its members interact with each other. The main objective of this paper is to examine through literature review, the strengths and weaknesses of ethnography as a research design method for researchers in the information communications and technology (ICT) field. This will therefore provide more insight on how ethnography can be applied in conducting some of the qualitative information communication and technologies studies, especially where in-depth understanding is required.
\end{abstract}

\begin{tabular}{|c|c|c|c|}
\hline Keywords & Ethnography, & Research & Methods, \\
\hline Information & Technology, & Qualitative & Methods, \\
\hline
\end{tabular}

\section{Introduction}

Scientific documents require scientific methodologies as tools for knowledge dissemination such as the manuscripts and dissertations. The scientific methods, studies the instruments necessary for the elaboration of any scientific work. Flanagan (2013), alludes to the fact that, scientific method is the most powerful tool for discovering truths about the world, exploration of new theories and performing their empirical validation. Therefore, scientific research can be qualitative or quantitative.

The qualitative research is concerned with the deeper understanding of a given problem. The objective of a qualitative research method is to produce an in-depth and illustrative information in order to understand various dimensions of the problem under investigation. It is concerned with the aspects of reality that cannot be quantified, focusing on the understanding and explanation of the dynamics of social relations. Maxwell (2013), advocates for a qualitative research for the universe meanings, motives, aspirations, beliefs, values and attitudes, which corresponds to a deeper space of relationships, processes and phenomena that cannot be reduced to the operationalization of variables. Quantitative research on the other hand, can be quantified and the results are therefore taken as representative enough for a comprehensive view of the entire population (Martin and Bridgmon, 2012). Quantitative research on the other hand adopts structured procedures and formal instruments for data collection and analysis of the numerical data and is performed through statistical tools. Table 1 below illustrates the main differences between quantitative and qualitative research methods. 
Table 1. Differences between quantitative and qualitative research methods

\begin{tabular}{|c|c|c|}
\hline Difference & $\begin{array}{c}\text { Quantitative } \\
\text { research }\end{array}$ & $\begin{array}{c}\text { Qualitative } \\
\text { research }\end{array}$ \\
\hline $\begin{array}{c}\text { Focus on understanding the } \\
\text { context of the problem }\end{array}$ & Smaller & Bigger \\
\hline Dimension of group studies & Smaller & Bigger \\
\hline $\begin{array}{c}\text { Proximity of the researcher to } \\
\text { the problem being studied }\end{array}$ & Smaller & Bigger \\
\hline Scope of the study in time & Immediate & Longer range \\
\hline Researcher's point of view & External & Internal \\
\hline $\begin{array}{c}\text { Theoretical framework and } \\
\text { hypotheses }\end{array}$ & Well structured & $\begin{array}{c}\text { Less } \\
\text { structured }\end{array}$ \\
\hline $\begin{array}{c}\text { Flexibility and exploratory } \\
\text { analysis }\end{array}$ & Lower & Higher \\
\hline
\end{tabular}

The study of the strengths and weaknesses of the ethnography research methodology has been of interest to several researchers. In practice, there are difficulties in choosing the most appropriate research methodology best suited for a given study. This paper intends to highlight an important contribution in this decision process, through the systematic literature of ethnography research method for use in the area of information technology.

\section{Literature Review}

Ethnography originated from the Greek word " $\varepsilon$ " $\theta v o \varsigma$ ", ethnos, meaning the folks, people or nation and " $\gamma \rho \alpha \dot{\varphi} \varphi \omega$ ", grapho, meaning "I write". Ethnography is therefore a systematic study of people and cultures. It involves the researcher observing the society to explore the cultural phenomena in relations to the study area. Ethnography, emerging from anthropology, and adopted by sociologists, is a qualitative methodology that lends itself to the study of the beliefs, social interactions, and behaviors of small societies, involving participation and observation over a period of time, and the interpretation of the data collected (Denzin and Lincoln, 2011). Though it is a time consuming type of research design, however, its main benefit is its depth, and therefore the contribution of rich insight to the subject being studied. The main tool for data collection technique is participant observation (Myers, 1999). Ethnography therefore, entails examining the participant's behavior under certain conditions with their interpretations of such behavior. Ethnography data consists of unstructured accounts and the analysis, which provides interpretation of meaning, and is done by the researcher, using observation, description and explanation (Reeves, Kuper and Hodges, 2008).

From this, ethnography therefore, is seen to be more of a method of data collection. Dewan (2018), explains that, this behavior may be shaped by the constraints which the participants feel is a result to the situations they may be in or the society they belong.

Having originated from the social sciences that focused on first hand study, ethnography therefore gives importance to studying what people do and say under a particular context. This involves lengthy contact with the people. Ethnography is therefore a presentation of empirical data on human societies and cultures. It can also be used in social sciences to study ethnic groups, formations, compositions, resettlements, social welfare characteristics, materiality, spirituality, and a people's ethno genesis. In ethnography, all records are observed and described to avoid casual explanations. The observation method towards a naturalistic anthropology is attributed to Malinowski and others like Boas, Margaret Mead (Freeman 1999; Shankman 2000). Ethnography has been subjected to theoretical works such as feminism, Marxism, actor network theory, activity theory, distributed cognition, symbolic interaction, grounded theory and many more.

\subsection{Use of Ethnography}

Ethnography emphasizes the perspective of seeing things from the side of those under study, to see the activities as social actions embedded within a socially organized domain that can be accomplished through the day to day activities of the participants. Ethnographers should be able to listen, show interest in what people do and what they say, so that they may carry out data collection (Hughes and Sharrock 2002). Hughes and Sharrock suggests that, in terms of data collection, data is often lying around in plain sight with nothing special and nothing hidden to look for. Given access, data can be very quickly collected. Hughes et al. 1994, identified some of the uses of ethnography as: for re-examination of previous studies from the initial thinking, to provide a general, but informed sense of the setting, to adapt focus over time in systems development, and to evaluate, verify and validate a set of already formulated design decisions.

\subsection{Ethnography and Design Implications}

Ethnography in design has been a matter of controversy because there are no panaceas for the problems of design, and arguably could not be (Anderson 1994; Plowman et al. 1995). The design would entail having universal character for the community. It therefore expected that ethnography would be a modest utility for the design, and the role of ethnography as we practice it, is primarily as an informational input into design. The input could be critical for computer designs as far as actual practice is concerned. Ethnography may therefore provide a framework for a specific analysis of technology and organizations. Dourish in his paper on implications for design, wrote that, the relationship between ethnography and design was subjected to a forensic lens and this relationship has been under examined. There are two consequences for this, one, it has led to rendering of design implications towards the end of otherwise competent ethnographies. Two, it has led to acceptance service relationship, which ignores the 
potential of ethnography as a critical role.

Ethnography with its emphasis on the situational observation and interactions in their natural settings, is suitable to bring social perspective on the system design such as human computer interaction (HCI). It impacts the kind of end user on real-time and real world based on human beings and consequently, the designers turn to social sciences for provision of insights and sensitivities that inform the design. Ethnography might provide the following: May provide additional domain knowledge, May provide overall view of a complex settings which would otherwise be difficult to obtain, May provide different perspectives of practices from a variety of stakeholders, May provide some level of scope assessment and limitations of systems and products, May provide a balanced view of the relationship between standardized processes, human skills, and how to deal with contingencies, Ethnography provides a fuller view of the real world view of the problems that need to be solved, Provides a detailed knowledge for routine ways in which technologies actually used and for what, and Provide a critique of those who offer simplistic technical or organizational solutions.

Ethnography is not only a tool for the designers, but also for anyone who wants to know what needs to be changed and how to go about changing it. It is always about asking questions such as 'What kind of a problem do we have?' how does the problem look like? and how does it manifest itself?'. These questions must be addressed before the designers provide solutions.

\section{How Ethnography Research Method Can Be Adopted in IS Research}

The use of ethnography in information systems research can be viewed under three types of ethnographies that are particularly relevant to the IS. These three types of ethnographies are: Organizational ethnographies, Digital ethnographies, and Design ethnographies. With these three types of ethnographies, the key challenges for IS research is that, the phenomena of interest are changing due to technological innovations. For example, from personal devices such as the wearables to a more digital, distributed and global technologies such as grid computing and digital traces. This means that the ethnographic methods ought to be adapting to better capture contemporary phenomena. Ethnographic research in the area of mobile, sensory and visual ethnography, are the future areas of IS research.

Internet technologies is also an emerging area of interest in ethnography. With the new multi spatial online connections that enables access across geographic spaces with its mobility that its users engage in through multiple devices, is an experience that spans different forms of interactions. The internet aspects form a very interesting cultural phenomena. They require ethnographic engagements to work out their meanings and how they shape our contemporary view of subjectivity, personhood, and sociality. The challenges faced by ethnographers as they handle internet, is the finding of coherent ways to carve out a researchable object from the mass of temporal and spatial complexity and the interweaving of the social and cultural processes that create the Internet and embeds it on everyday life. This demands for adaptive situated methodological response due to the diverse, flexible and heterogeneous nature of the internet.

\section{Ethnography - Comparison of Strengths, Weaknesses among Qualitative Methods}

Ethnography just like any other research design or methodology comes with both its strengths and weaknesses. It can be said to be a time consuming type of research method, but on the positive side, it offers an in-depth approach to conducting a research, and therefore the contribution of rich insight to the subject being studied. The main weakness is that it lacks breadth, as the focus is typically on one particular situation or phenomenon, leading to a criticism of lack of generalizability (Iacono, Brown, and Holtham, 2009).

A study by Almeida et al., (2017), showed the trend of qualitative methods utilization on published research studies from year $2008 \mathrm{t}$ year 2017 as indexed by web of science (WoS), Scopus and EBSCO. The study identified around 23 million studies that used qualitative methods. As shown in the figure below, ethnography scored very low. Meaning, the utilization of the qualitative method is still underutilized. 


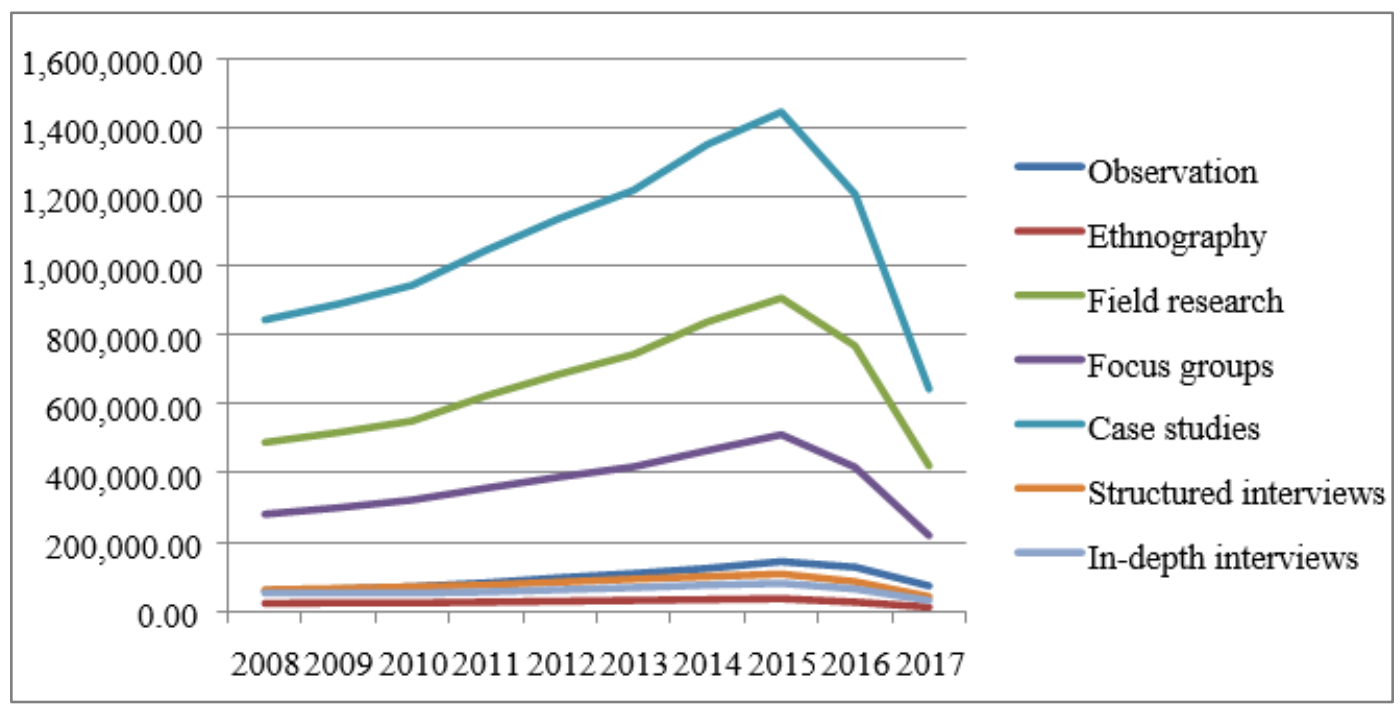

Source: Almeida et al., (2017)

Figure 1. Qualitative research methods utilization for publications

\section{Qualitative Research Methods Descriptive}

Observation - this is a systematic process of collecting information whereby researchers observe a given phenomenon in their natural settings. This method is used especially when a given topic is relatively unexplored and needs to be understood in detail under the given phenomena, while maintaining the environmental conditions for which it occurs.

Observation is a good way for collecting simultaneous data for an event occurrence, without interfering with the event occurrence. This method is very sensitive on the researcher's independence, because the interpretation and analysis of data is exclusively lead by the researcher.

Ethnography - involves observation and conducing of interviews with the participants at their natural setting. The researcher must understand how the participants perceive an event. Observation and observation and ethnography are very similar methods. However, Charmaz (2006) states that, ethnography ensures that the researcher have a holistic view and must examine the details of all the aspects of the event available.

Field research - allows researchers to have an in-depth perception about the participants and processes. Data collection is carried out in the field. According to Blackstone (2012), the social facts may be discovered over time during the course of the field research, but not may not appear in a first moments of the study period. This research method may not be easy to generalize because of the very large number of participants and groups, which makes documenting observations a challenging process.

Focus groups - is a good method for investigating complex behavior involving the researcher interaction with the participants. According to Acocella (2012), there are two main characteristics of focus groups; the group as a source of information and the heuristic value involving the kind of interaction that emerges.

The case studies - these provides means for investigating complex situations with multiple variables. Case studies are appealing in advancing field knowledge base for innovation and challenging the current theoretical assumptions. They pose difficulty for cause effect analysis and generalization.

Structured interviews - are used to compare responses from interviews. They offer high response rates from interviewees who are expected to have past experiences of the proposed hypothetical situations.

In-depth interviews - are unstructured, direct, and personal interview for each respondent. They start with generic questions then move into free speaking about the topic. It provides rich information and offers opportunity to ask and follow up questions, justify and probe answers.

Table 2 below illustrates a summary of the strengths and weaknesses of ethnography design alongside other designs. 
Table 2. Comparison among qualitative methods

\begin{tabular}{|c|c|c|}
\hline Method & Strength & Weakness \\
\hline Ethnography & $\begin{array}{l}\text { - It's based on observation and interviews with } \\
\text { direct involvement of the authors. } \\
\text { - } \quad \text { It provides in-depth findings. } \\
\text { - Is suitable for exploring new lines of research. }\end{array}$ & $\begin{array}{l}\text { - It lacks breadth, as the focus is typically on one } \\
\text { particular situation or phenomenon, leading to a } \\
\text { criticism of lack of generalizability (Iacono, Brown, } \\
\text { and Holtham, 2009). } \\
\text { - Very time consuming. } \\
\text { - It's difficult to get concise and precise conclusions. } \\
\text { The researcher needs to have a deep knowledge of } \\
\text { the problem domain. }\end{array}$ \\
\hline Observation & $\begin{array}{l}\text { - It collects data simultaneously with the event } \\
\text { occurrence. } \\
\text { Its unobtrusive way, which it's not dependent on } \\
\text { upon someone's response. } \\
\text { - } \quad \text { Flexible and oriented to knowledge discovery. }\end{array}$ & $\begin{array}{l}\text { - } \quad \text { Very time consuming. } \\
\text { - } \quad \text { Its dependent on the observer's impartiality. } \\
\text { - } \quad \text { It's difficult to collect data in real time. }\end{array}$ \\
\hline $\begin{array}{l}\text { Structured } \\
\text { interviews }\end{array}$ & $\begin{array}{l}\text { - Its well-structured and easy to compare } \\
\text { respondent's answers. } \\
\text { It can reach a large sample. } \\
\text { - It's easy to replicate. } \\
\text { - Quick to conduct an interview. }\end{array}$ & $\begin{array}{l}\text { - It's very rigid } \\
\text { - } \quad \text { Has low flexibility in the response's choice. } \\
\text { It's difficult to obtain detailed data. } \\
\text { Preparing an interview can become time consuming. }\end{array}$ \\
\hline Field research & $\begin{array}{l}\text { - Is adequate in getting very detailed data. } \\
\text { It emphasizes the role and relevance of social } \\
\text { context. }\end{array}$ & $\begin{array}{l}\text { - It's difficult to generalize and get data from a very } \\
\text { large number of people or groups. } \\
\text { It depends on the observer's impartiality. } \\
\text { Documenting observations may become a } \\
\text { challenging process. }\end{array}$ \\
\hline Focus groups & $\begin{array}{l}\text { - Can get adequate detailed information about } \\
\text { personal and group data. } \\
\text { - } \quad \text { It offers an opportunity to seek clarification. } \\
\text { It lowers the costs and time when compared to } \\
\text { individual interviews. }\end{array}$ & $\begin{array}{l}\text { It's hard to control and manage. } \\
\text { It's difficult to get the participation of people. } \\
\text { It cannot be representative of all population. }\end{array}$ \\
\hline Case studies & $\begin{array}{l}\text { It provides detailed information about } \\
\text { individuals. } \\
\text { It offers a good opportunity for innovation and to } \\
\text { change current theoretical assumptions. } \\
\text { It can be a good alternative or complement to } \\
\text { focus groups. }\end{array}$ & $\begin{array}{l}\text { - It's difficult to establish cause-effect connections. } \\
\text { It's hard to generalize from a small number of case } \\
\text { studies. } \\
\text { The ethical issues, especially confidentiality, may } \\
\text { arise. } \\
\text { It's difficult to create a case study that suits all } \\
\text { subjects. }\end{array}$ \\
\hline $\begin{array}{l}\text { In-depth } \\
\text { interviews }\end{array}$ & $\begin{array}{l}\text { - It can be adjusted to get detailed and insightful } \\
\text { information on a given domain. } \\
\text { It needs only fewer participants to provide useful } \\
\text { and relevant insights. } \\
\text { - It can be performed in informal environments. }\end{array}$ & $\begin{array}{l}\text { - Its time consuming and relatively high cost. } \\
\text { Takes longer to process to verify and extract } \\
\text { compared information. } \\
\text { The participants should be carefully chosen to avoid } \\
\text { bias. } \\
\text { - It's not generalizable. }\end{array}$ \\
\hline
\end{tabular}

\section{Methods for Literature Review}

The main objective for conducting the literature review was to provide an overview of steps carried out while reviewing relevant articles for the study objective. Levy \& Ellis (2006), proposed a generic framework for conducting literature reviews. Their model proposed by Levy and Ellis follows a systematic data processing approach with three steps involved; that is, literature search and screening, content extraction and analysis from relevant articles and literature review writing.

This study used the narrative review type of literature review. The aim was to summarize or synthesize the literature that has been published before based on this particular research area (qualitative data analysis methods), but did not opt for generalization on what was reviewed. Paré et al., (2015), summarized the narrative literature review process and the search strategies adopted in this study in table below.

This type of review is very useful in gathering volumes of literature in a specific subject area and synthesizing it. It primary goal was to provide comprehensive background for understanding the current knowledge and highlighted the significance of the new research area (Cronin et al., 2008). Other literature review process not adopted in this study were; Descriptive or mapping review, scoping review, systematic review, umbrella review, realist review, and critical review. 
Table 3. Typology of narrative literature review

\begin{tabular}{|c|c|c|c|c|c|}
\hline $\begin{array}{c}\text { Literature } \\
\text { review type }\end{array}$ & Objective & Search strategy & $\begin{array}{c}\text { Appraisal of } \\
\text { included studies }\end{array}$ & Analysis and synthesis & Source \\
\hline $\begin{array}{c}\text { Narrative } \\
\text { review }\end{array}$ & $\begin{array}{c}\text { Objective is to summarize or } \\
\text { on a particular topic but does not } \\
\text { seek generalization or } \\
\text { cumulative knowledge from } \\
\text { what is reviewed. }\end{array}$ & $\begin{array}{c}\text { Sesearchers usually } \\
\text { select studies that } \\
\text { support their own } \\
\text { view. }\end{array}$ & $\begin{array}{c}\text { No formal quality } \\
\text { or risk of bias } \\
\text { assessment of } \\
\text { included primary } \\
\text { studies is required. }\end{array}$ & $\begin{array}{c}\text { Narrative using thematic } \\
\text { analysis, chronological } \\
\text { order, conceptual } \\
\text { frameworks, content } \\
\text { analysis or other } \\
\text { classification criteria. }\end{array}$ & $\begin{array}{c}\text { (Cronin et al., } \\
\text { al., 2008; Green et } \\
\text { Ellis, 2006; } \& \\
\text { Webster \& } \\
\text { Watson, 2002) }\end{array}$ \\
\hline
\end{tabular}

Source: Paré et al., (2015)

\section{Methodology Flowchart Used for the Selection of the Articles for the Study}

The researcher examined the relevant abstracts and full text articles with a total of 40 published article. 26 articles were incorporated into this review as per the flow diagram in figure 2 , of citation retrieval and selection of articles.

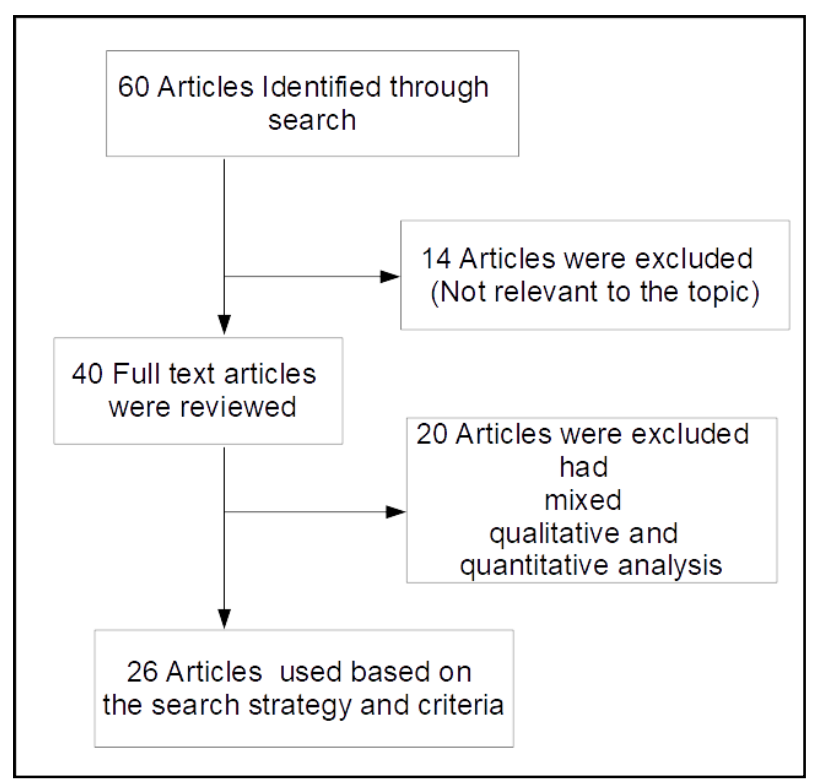

Figure 2. Methodology flowchart used for the selection of articles in the study

The search and selection criteria was conducted based on PRISMA statement criteria

\section{Conclusions}

It is the role of scientific studies to expand the horizons of theories and explain various phenomena of society. Through research methods, scientific studies are carried out to allow specific analysis according to a suitable methodology chosen by the researcher. It is the prerogative of the researcher to choose the research methodology that best suit the situation under investigations. The choice of research method should take into account the advantages and disadvantages of each method depending on the nature of the research study. The ethnography may require certain periods of time in the 'field' and emphasize details of observational evidence.

Ethnography as a method allows a researcher to give special attention to the qualitative social boundaries that are unbundled from territorial space. Ethnography offers the potential ideal method for undertaking research where the community and its members interact with each other. Ethnography is believed to be unproblematic if accepted as a research method in information technology. That is to say, ethnography is a research design based on different ontological and epistemological foundations that require the researcher to adhere to the natural sciences.

\section{REFERENCES}

[1] Acocella, I. (2012). The focus group in social research: advantages and disadvantages. Quality \& Quantity, 46(4), 1125-1136.

[2] Almeida, Fernando \& Faria, Daniel \& Queirós, André. (2017). Strengths and Limitations of Qualitative and Quantitative Research Methods. European Journal of Education Studies. 3. 369-387. 10.5281/zenodo.887089.

[3] Almeida, Fernando \& Faria, Daniel \& Queirós, André. (2017). Strengths and Limitations of Qualitative and Quantitative Research Methods. European Journal of Education Studies. 3. 369-387. 10.5281/zenodo.887089.

[4] Blackstone, A. (2012). Principles of sociological inquiry: qualitative and quantitative methods. Retrieved from https://2012books.lardbucket.org/books/sociologicalinquiry -principles-qualitative-and-quantitative-methods/index.html

[5] Charmaz, K. (2006). Constructing grounded theory: a practical guide through qualitative analysis. London, United Kingdom: Sage.

[6] Cronin P., Ryan F., Coughlan M. Undertaking a literature review: a step-by-step approach. British Journal of Nursing. 2008;17(1):38-43.

[7] Denzin, N. K. \& Lincoln (2011). The Sage Handbook of Qualitative Research. Sage Publications: USA.

[8] Duque, Ezequiel \& Ishitani, Lucila \& Mol, Artur \& Machado, Mônica \& Eugênio Neves, Daniel \& Martins, Scheila \& Santos, Luana. (2019). The use of ethnography in computer science research: a systematic literature review. Revista Tecnologiae Sociedade. 15.10.3895/rts.v15n35.780 1. 
[9] H. Sharp, Y. Dittrich and C. R. B. de Souza, "The Role of Ethnographic Studies in Empirical Software Engineering," in IEEE Transactions on Software Engineering, vol. 42, no. 8, pp. 786-804, 1 Aug. 2016. doi: 10.1109/TSE.2016.25198 87

[10] http://citeseerx.ist.psu.edu/viewdoc/download?doi=10.1.1.5 $59.5767 \&$ rep $=$ rep $1 \&$ type $=$ pdf

[11] http://eprints.gla.ac.uk/705/1/JETMpaper.pdf

[12] https://dl1.cuni.cz/pluginfile.php/440889/mod_resource/con tent/1/Hine $\% 2 \mathrm{C} \% 20$ ChristineEthnography $\% 20$ for $\% 20$ the $\%$ 20Internet $\% 20 \_\% 20$ embedded $\% 2 \mathrm{C} \% 20$ embodied $\% 20$ and $\% 20$ everyday-Bloomsbury\%20Academic $\% 20 \% 282015 \% 2$ 9.pdf

[13] https://en.wikipedia.org/wiki/Ethnography

[14] https://pdfs.semanticscholar.org/0458/6be5a2f9d342d2705e f626524bffd3ead1b5.pdf

[15] https://pdfs.semanticscholar.org/7eb8/0bfcbad0451b5a393a 188dac740713391af5.pdf

[16] https://pdfs.semanticscholar.org/d8b4/103f971ac274162b65 c2e2c1f17ca50e580c.pdf

[17] https://www.depts.ttu.edu/education/our-people/Faculty/add itional_pages/duemer/epsy_6304_class_materials/Ethnogra phic-and-qualitative-research-design-and-why-it-doesnt-wo rk.pdf

[18] https://www.herd.org.np/uploads/frontend/Publications/Pub licationsAttachments1/1480653184-Ethnography_1.pdf

[19] https://www.spotless.co.uk/insights/ethnography-when-andhow/

[20] Iacono, J. Brown, A., \& Holtham, C., (2009). Research Methods - a Case Example of Participant Observation: Electronic Journal of Business Research Methods Volume 7 Issue 12009 (39 - 46)

[21] Kane, Hilary \& Ragsdell, Gillian \& Oppenheim, Charles. (2006). Knowledge management methodologies. The Electronic Journal of Knowledge Management. 4. 141-152.

[22] Levy Y., Ellis T.J. A systems approach to conduct an effective literature review in support of information systems research. Informing Science. 2006; 9:181-211

[23] Liberati et al., (2009). The PRISMA Statement for Reporting Systematic Reviews and Meta-Analyses of Studies That Evaluate Health Care Interventions: Explanation and Elaboration. Journal of clinical epidemiology. 62. e1-34. 10.1016/j.jclinepi.2009.06.006.

[24] Myers, M.D. (1999). 'Investigating Information Systems with Ethnographic Research' in Communications of the AIS, Vol. 2, Article 23 pp. 1-20

[25] Paré G., Trudel M.-C., Jaana M., Kitsiou S. Synthesizing information systems knowledge: A typology of literature reviews. Information \& Management. 2015;52(2):183-199.

[26] Reeves, Kuper and Hodges. (2008). Qualitative research methodologies: ethnography. British Medical Journal. 337: a1020. 